\title{
Determination of land salinization causes via land cover and hydrological process change detection in a typical part of Songnen Plain
}

\author{
WANG Zhiyong ${ }^{1,2}$, "LI Lijuan ${ }^{1}$ \\ 1. Institute of Geographic Sciences and Natural Resources Research, CAS, Beijing 100101, China; \\ 2. University of Chinese Academy of Sciences, Beijing 100049, China
}

\begin{abstract}
Causes of land salinization were determined via land cover and hydrological process change detection in a typical part of Songnen Plain. The area of saline land increased from $4627 \mathrm{~km}^{2}$ in 1980 to $5416 \mathrm{~km}^{2}$ in 2000 , and then decreased to $5198 \mathrm{~km}^{2}$ in 2015 . The transformation between saline land and other land covers happened mainly before 2000, and saline land had transformation relationship mainly with cropland, grassland, and water body. From 1979 to 2007, groundwater depth fluctuated to increase and was mainly deeper than $3.3 \mathrm{~m}$. Spatially, the area of the region where groundwater depth was deeper than $3.3 \mathrm{~m}$ increased from $46.7 \%$ in 1980 to $84 \%$ in 2000 , while the area of the region almost occupied the whole region after 2000. Precipitation and evaporation changed little, while runoff decreased substantially. Shallow groundwater, change of cropland, grassland, and water body induced from human activities and decrease of runoff and increase of irrigation and water transfer from outer basin were the main reasons for land salinization before 2000. After 2000, groundwater with relatively great depth could not exert great influence on land salinization. Protection of grassland and wetland prevented the increase of the area of saline land.
\end{abstract}

Keywords: change detection; hydrological process; land cover; land salinization; Songnen Plain

\section{Introduction}

Land salinization is one of the most common land degradation processes (UNEP, 1991). More than $77 \mathrm{~m}$ ha (million hectares) of land were salt-affected and about $43 \mathrm{~m}$ ha were attributed to secondary salinization at global scale in 2007 (FAO, 2007). Moreover, some estimates indicated that one-third of the irrigated land in the major countries with irrigated agriculture was badly affected by salinity or expected to be salinized in the near future (Lambert et al., 2002; Akhtar et al., 2013). Land salinization often occurs particularly in arid

Received: 2017-10-12 Accepted: 2018-01-26

Foundation: Key Deployment Project of CAS, No.KFZD-SW-314; National Natural Science Foundation of China, No.91547114

Author: Wang Zhiyong (1988-), PhD Candidate, specialized in water and salt cycle. E-mail: wangzy8809@gmail.com

"Corresponding author: Li Lijuan, Professor, E-mail: lilj@igsnrr.ac.cn 
or semiarid areas (Masoud and Koike, 2006), where low rainfall, high evapotranspiration rates or soil textural characteristics impede the washing out of the salts which subsequently built-up in the soil surface layers. Threats of land salinization on ecosystem and environment are obvious (Line et al., 2010). Accumulation of soluble salts in the soil is one of the main limiting factors for agriculture by decreasing the soil productivity (Rengasamy, 2002), limiting the growth of crops (Datta et al., 2002; Yamaguchi and Blumwald, 2005), constraining agricultural productivity (Qadir et al., 2008) and even leading to the abandonment of arable lands (Ding et al., 2011). Besides, it also poses threats on environment by increasing the salinity of water, decreasing biodiversity of ecosystem (Halse et al., 2003), and affecting other major soil degradation phenomena such as soil dispersion, soil erosion (García-Ruiz, 2010), and engineering problems (Metternicht and Zinck, 2003). Given these adverse impacts, detecting its causes is important for better management practices.

Songnen Plain, which is the largest production base of commodity grain in China, has 3.2 $\mathrm{m}$ ha saline land (21\% of the area of the Plain) (Wang et al., 2009) and is the biggest distribution area of soda saline land in China (Gu, 2010). Many reasons resulted in the occurrence of the land salinization of Songnen Plain. Neo-plate tectonics provided the sources and transport path, and generated the accumulation environment (Wang et al., 1985). Shallow depth groundwater provided the solvent and carrier for the dissolving and rise of the soil salt (Song et al., 2000; Zhang et al., 2000). Arid or semiarid climate provided the power for the rise of the water and salt in the soil profile (Yu et al., 1993; Liu et al., 2002). In the last several decades, land salinization has been aggravated constantly. Human activities, which lead to the changes of the hydrological process, are the main driving factors to the soil salinization (Liu et al., 2005). Moreover, shallow depth groundwater and ponding rainwater lead to the primary land salinization, while the secondary land salinization was induced from the significant decrease of the chances and occurrence frequency of flooding and waterlogging in the low-lying plains (Yang et al., 2010). Even many researches had paid attention to saline land of Songnen Plain, the detailed spatio-temporal transformation relationship with other land covers and long-term hydrological process, especially, the spatio-temporal distribution of groundwater were not depicted at the same time. In this study, a typical part of Songnen Plain was chosen to analyze its causes for land salinization by revealing the spatio-temporal change of land covers and hydrological process simultaneously.

\section{Study area}

Land salinization, which mainly distributed in the western part, was a severe problem in Songnen Plain. This part including 5 counties where land salinization problem was typical was chosen as the study area (Figure 1). The area of the typical part was $25,664 \mathrm{~km}^{2}$. The terrain decreased from Northwest to Southeast and the altitude of the whole part was mainly from 100 to $200 \mathrm{~m}$. The Taoer River flows through this part and runs toward Nenjiang River. The flat terrain made the precipitation and runoff from the upper reach accumulated in this area and evaporation was the main means of discharge. High evaporation (1194 mm, Ф20 $\mathrm{cm}$ pan evaporation), low precipitation $(386 \mathrm{~mm})$, and a large amount of irrigation created a favorable condition for the aggregation of soil salt on the land surface. 


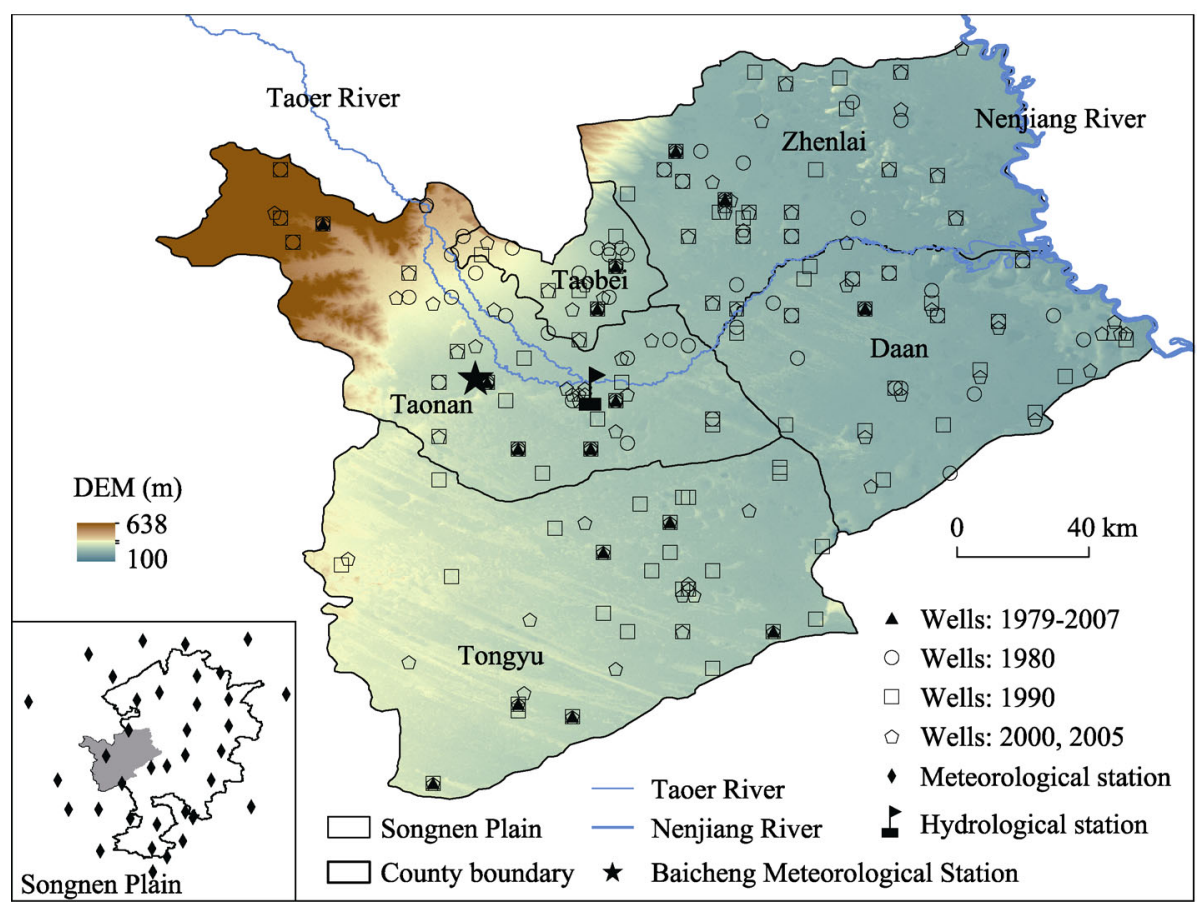

Figure 1 Location of the typical part of Songnen Plain

\section{Data and methods}

\subsection{Land cover database}

Six land cover databases, with a mapping scale of 1:1,000,000, of the years 1980, 1990, 2000, 2005, 2010, and 2015 were collected from 'Data Center for Resources and Environmental Sciences Chinese Academy of Sciences' (website: http://www.resdc.cn/Default.aspx). The data source for the land cover database was Landsat MSS/TM/ETM/OLI, China-Brazil Earth Resources Satellite, Small Satellite Constellation for Environment and Disaster Monitoring, and Forecasting HJ-1 satellite digital images (Liu et al., 2014; Liu et al., 2015). More detailed information about this land cover database could be found in previous reports (Liu et al., 2010).

In this paper, based on the classified 25 second-level land cover types, the land cover data were grouped into seven classes: cropland, woodland, grassland, water body (including swampland), built-up area, unused land, and saline land to reveal the spatio-temporal dynamic of the saline land.

\subsection{Hydrological data}

Hydrological data included groundwater depth, precipitation, evaporation, and runoff.

Groundwater depth collected from the 'Northeast Institute of Geography and Agroecology, Chinese Academy of Sciences'. The data included the groundwater depth every 5 days from 16 wells from 1979 to 2007, annual mean groundwater depth every 5 days from 61 wells in 1980, annual mean groundwater depth every 5 days from 98 wells in 1990, annual mean 
groundwater depth every 5 days from 86 wells in 2000 and 2005. The data from 1979 to 2007 were used for analyzing the temporal variation of groundwater depth. The data in 1980, 1990, 2000, and 2005 were used for analyzing the spatial distribution of groundwater depth based on the spatial interpolation by using the Kriging interpolation method. The spatial distribution of groundwater depth in 2010 and 2015 was also analyzed based on "Monthly report of groundwater dynamics", which was opened for inquiry at website (http://www.hydroinfo.gov.cn/).

Annual precipitation and evaporation from 1960 to 2015 were collected from Baicheng Meteorological Station for the temporal variation analysis. Runoff from 1983 to 2006 at Taonan Hydrological Station was collected for the temporal variation analysis. Spatial interpolation data of precipitation in 1980, 1990, 2000, 2005, 2010, and 2015 were collected for the analysis of spatial distribution. The dataset is provided by Data Center for Resources and Environmental Sciences, Chinese Academy of Sciences (RESDC) (http://www.resdc.cn). Data on annual pan evaporation $(\Phi 20 \mathrm{~cm})$ of Songnen Plain in 1980, 1990, 2000, 2005, 2010, and 2015 at 36 meteorological stations were collected for spatial interpolation by using the Spline method. Spatial distribution in the typical area was cut out from the whole area for spatial dynamic analysis.

\subsection{Transfer matrix}

Land cover transfer matrix was used for the analysis of transformation between saline land and other kinds of land covers. Details about this method could be found from previous studies (Lai et al., 2014; Li et al., 2016).

\subsection{Gravity}

Gravity was the geographic center that was defined as a point constructed from the average longitude and latitude weighted by the area of a particular kind of land cover patch individually. Gravity represented its spatial distribution center. The change of the gravities' location showed the change of the spatial distribution of a particular kind of land cover. Gravity was used to represent the spatial distribution center of saline land in this study.

The expression for Gravity calculation was listed as following:

$$
\begin{gathered}
X_{t}=\sum_{i=1}^{N} C_{t i} \times X_{i} / \sum_{i=1}^{N} C_{t i} \\
Y_{t}=\sum_{i=1}^{N} C_{t i} \times Y_{i} / \sum_{i=1}^{N} C_{t i}
\end{gathered}
$$

where $X_{t}$ and $Y_{t}$ are the longitude and latitude of a particular land cover in the year $t ; C_{t i}$ is the area of the number $i$ patch of the particular land cover in the year $t ; X_{i}$ and $Y_{i}$ are the longitude and latitude of the number $i$ patch for the particular land cover. Gravities of saline land and water body were calculated by using the spatial analysis software Arcgis 10.2.

\section{Results}

\subsection{Spatio-temporal change of saline land area}

In the typical part of Songnen Plain, cropland, grassland, saline land, and water body were the major land covers. From 1980 to 2015, the mean area of saline land was $5170 \mathrm{~km}^{2}$ (Table 1). 
The area of saline land increased from $4627 \mathrm{~km}^{2}$ in 1980 to $5416 \mathrm{~km}^{2}$ in 2000 , and then decreased to $5198 \mathrm{~km}^{2}$ in 2015 . Most of the region was occupied by saline land except for the built-up area in Taobei and the riversides of Taoer and Nenjiang rivers (Figure 2). Saline land almost occupied the southeast part of the whole area. The spatial distribution centers have the almost similar location with the spatial center of the whole area (Figure 2). All of this indicated that the saline land distributed uniformly in the study area. The distribution center moved from Northwest to Southeast when the area of saline land increased. In the 5 counties, Da'an was the major distribution region. The bigger the area of saline land, the closer to Da'an the distribution center. The change of saline land in Da'an was the major reason for the change of spatial distribution.

Table 1 Area of land covers in the typical part of Songnen Plain $\left(\mathrm{km}^{2}\right)$

\begin{tabular}{cccccccc}
\hline Year & Cropland & Woodland & Grassland & Water body & Built-up land & Unused land & Saline land \\
\hline 1980 & 9259 & 572 & 6447 & 3769 & 531 & 459 & 4627 \\
1990 & 9382 & 388 & 5856 & 3845 & 552 & 504 & 5137 \\
2000 & 11816 & 1205 & 3325 & 3185 & 567 & 150 & 5416 \\
2005 & 12003 & 1194 & 3363 & 3067 & 565 & 150 & 5322 \\
2010 & 11983 & 1193 & 3363 & 3066 & 586 & 150 & 5323 \\
2015 & 13278 & 1202 & 3327 & 1896 & 613 & 150 & 5198 \\
\hline
\end{tabular}

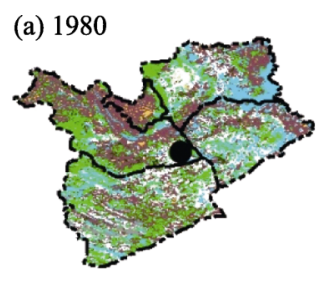

(e) 2010

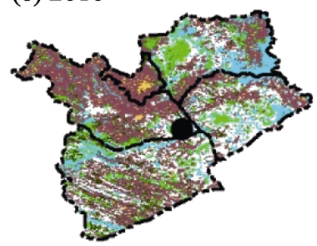

(b) 1990

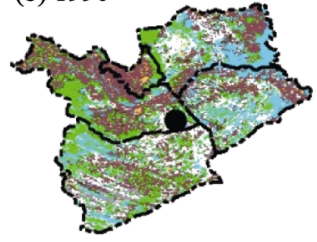

(f) 2015

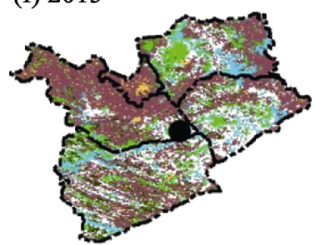

(c) 2000

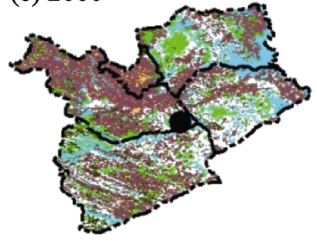

(d) 2005
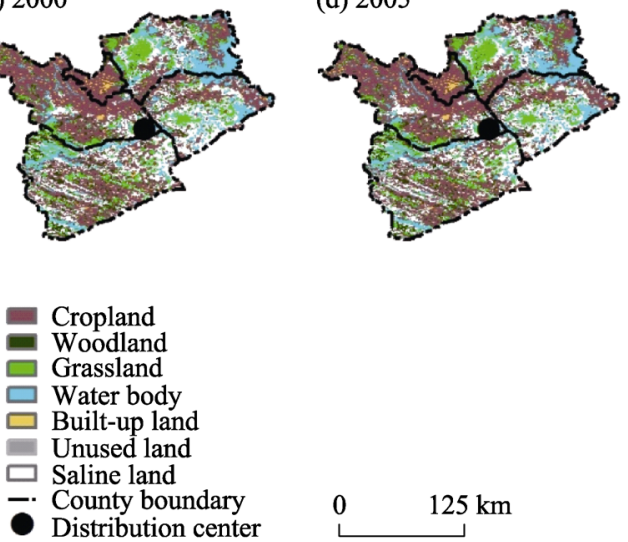

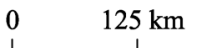

Figure 2 Land covers of the typical part of Songnen Plain

\subsection{Transformation of saline land}

Transformation among different land covers was calculated (Table 2). From 1980 to 1990, saline land transformed mostly from grassland $\left(1044 \mathrm{~km}^{2}\right)$, cropland $\left(831 \mathrm{~km}^{2}\right)$, and water body $\left(408 \mathrm{~km}^{2}\right)$ into cropland $\left(704 \mathrm{~km}^{2}\right)$, grassland $\left(627 \mathrm{~km}^{2}\right)$, and water body $\left(477 \mathrm{~km}^{2}\right)$. From 1990 to 2000 , saline land transformed mostly from grassland $\left(965 \mathrm{~km}^{2}\right)$, cropland $\left(831 \mathrm{~km}^{2}\right)$ and water body $\left(704 \mathrm{~km}^{2}\right)$ into cropland $\left(1026 \mathrm{~km}^{2}\right)$, grassland $\left(768 \mathrm{~km}^{2}\right)$ and water body $\left(379 \mathrm{~km}^{2}\right)$. In the periods of 2000 to 2005,2005 to 2010 , and 2010 to 2015, the transformation between saline land and other land covers was slight. Generally, before 2000, saline land transformed from cropland, grassland, and water body dramatically, but after 2000, there was almost no transformation between saline land and other land covers. 
Table 2 Transfer matrix of land covers in the typical part of Songnen Plain $\left(\mathrm{km}^{2}\right)$

\begin{tabular}{|c|c|c|c|c|c|c|c|c|c|}
\hline & & Cropland & Woodland & Grassland & $\begin{array}{r}\text { Water } \\
\text { body }\end{array}$ & $\begin{array}{c}\text { Built-up } \\
\text { land }\end{array}$ & $\begin{array}{c}\text { Unused } \\
\text { land }\end{array}$ & $\begin{array}{r}\text { Saline } \\
\text { land }\end{array}$ & Total \\
\hline & & \multicolumn{8}{|c|}{1990} \\
\hline \multirow{9}{*}{1980} & Cropland & 6521 & 130 & 1016 & 419 & 291 & 51 & 831 & 9259 \\
\hline & Woodland & 203 & 126 & 135 & 27 & 6 & 8 & 67 & 572 \\
\hline & Grassland & 1125 & 69 & 3595 & 450 & 78 & 86 & 1044 & 6447 \\
\hline & Water body & 472 & 16 & 372 & 2439 & 28 & 34 & 408 & 3769 \\
\hline & Built-up land & 295 & 4 & 62 & 23 & 74 & 12 & 61 & 531 \\
\hline & Unused land & 62 & 7 & 49 & 10 & 5 & 247 & 79 & 459 \\
\hline & Saline land & 704 & 36 & 627 & 477 & 70 & 66 & 2647 & 4627 \\
\hline & Total & 9382 & 388 & 5856 & 3845 & 552 & 504 & 5137 & 25664 \\
\hline & & \multicolumn{8}{|c|}{2000} \\
\hline \multirow{9}{*}{1990} & Cropland & 7022 & 366 & 478 & 364 & 308 & 13 & 831 & 9382 \\
\hline & Woodland & 168 & 132 & 37 & 11 & 4 & 1 & 35 & 388 \\
\hline & Grassland & 2333 & 432 & 1625 & 380 & 67 & 54 & 965 & 5856 \\
\hline & Water body & 705 & 54 & 336 & 2016 & 26 & 4 & 704 & 3845 \\
\hline & Built-up land & 319 & 16 & 50 & 19 & 82 & 1 & 65 & 552 \\
\hline & Unused land & 243 & 55 & 31 & 16 & 12 & 55 & 92 & 504 \\
\hline & Saline land & 1026 & 150 & 768 & 379 & 68 & 22 & 2724 & 5137 \\
\hline & Total & 11816 & 1205 & 3325 & 3185 & 567 & 150 & 5416 & 25664 \\
\hline & & \multicolumn{8}{|c|}{2005} \\
\hline \multirow{9}{*}{2000} & Cropland & 11765 & 5 & 19 & 10 & 1 & 0 & 16 & 11816 \\
\hline & Woodland & 14 & 1187 & 3 & 0 & 0 & 0 & 1 & 1205 \\
\hline & Grassland & 56 & 1 & 3221 & 8 & 0 & 0 & 39 & 3325 \\
\hline & Water body & 121 & 0 & 19 & 3008 & 0 & 0 & 37 & 3185 \\
\hline & Built-up land & 3 & 0 & 0 & 0 & 564 & 0 & 0 & 567 \\
\hline & Unused land & 0 & 0 & 0 & 0 & 0 & 150 & 0 & 150 \\
\hline & Saline land & 44 & 1 & 101 & 41 & 0 & 0 & 5229 & 5416 \\
\hline & Total & 12003 & 1194 & 3363 & 3067 & 565 & 150 & 5322 & 25664 \\
\hline & & \multicolumn{8}{|c|}{2010} \\
\hline \multirow{8}{*}{2005} & Cropland & 11974 & 0 & 5 & 0 & 23 & 0 & 2 & 12003 \\
\hline & Woodland & 1 & 1193 & 0 & 0 & 0 & 0 & 0 & 1194 \\
\hline & Grassland & 5 & 0 & 3358 & 0 & 0 & 0 & 0 & 3363 \\
\hline & Water body & 1 & 0 & 0 & 3066 & 0 & 0 & 0 & 3067 \\
\hline & Built-up land & 2 & 0 & 0 & 0 & 563 & 0 & 0 & 565 \\
\hline & Unused land & 0 & 0 & 0 & 0 & 0 & 150 & 0 & 150 \\
\hline & Saline land & 1 & 0 & 0 & 0 & 0 & 0 & 5321 & 5322 \\
\hline & Total & 11983 & 1193 & 3363 & 3066 & 586 & 150 & 5323 & 25664 \\
\hline
\end{tabular}


(Continued)

\begin{tabular}{cccccccccc}
\hline & Cropland & Woodland & Grassland & $\begin{array}{c}\text { Water } \\
\text { body }\end{array}$ & $\begin{array}{c}\text { Built-up } \\
\text { land }\end{array}$ & $\begin{array}{c}\text { Unused } \\
\text { land }\end{array}$ & $\begin{array}{c}\text { Saline } \\
\text { land }\end{array}$ & Total \\
\hline \multirow{2}{*}{2010} & & & & 2015 & & & & \\
\hline & Cropland & 11874 & 26 & 21 & 14 & 23 & 0 & 25 & 11983 \\
& Woodland & 17 & 1173 & 1 & 0 & 2 & 0 & 0 & 1193 \\
& Grassland & 88 & 0 & 3261 & 4 & 3 & 0 & 7 & 3363 \\
& Water body & 1162 & 2 & 11 & 1867 & 1 & 0 & 23 & 3066 \\
& Built-up land & 20 & 0 & 1 & 0 & 565 & 0 & 0 & 586 \\
& Unused land & 0 & 0 & 0 & 0 & 1 & 149 & 0 & 150 \\
& Saline land & 117 & 1 & 32 & 11 & 18 & 1 & 5143 & 5323 \\
& Total & 13278 & 1202 & 3327 & 1896 & 613 & 150 & 5198 & 25664 \\
\hline
\end{tabular}

\subsection{Change of hydrological process}

From 1979 to 2007, groundwater depth of the 16 wells was almost greater than $1.7 \mathrm{~m}$ and mainly greater than $3.3 \mathrm{~m}$ (Table 3 and Figure 3). In the 16 wells, there were 15 wells that the ratio between the data number which was larger than $1.7 \mathrm{~m}$ and the whole data number was bigger than $80 \%$. There were 8 wells that ratio between the data number which was larger than $3.3 \mathrm{~m}$ was bigger than $70 \%$ (Table 3 ). The groundwater depth had a relatively regular seasonal pattern that the groundwater rose in spring, dropped down in summer with fluctuation, and rose again in autumn and winter (Figure 3). In the long run, from 1979 to 2007 , the groundwater depth of 13 wells had an increasing trend and the groundwater depth changed with fluctuation in the other 3 wells.

Groundwater depth was larger than $3.3 \mathrm{~m}$ in the most part of the whole area (Figure 5). In 1980, groundwater depth was mainly less than $1.7 \mathrm{~m}(27 \%)$ and larger than $3.3 \mathrm{~m}(46.7 \%)$. In 1990, groundwater depth was mainly $2.4-3 \mathrm{~m}(14.5 \%)$ and larger than $3.3 \mathrm{~m}(65 \%)$. In 2000 and 2005, groundwater depth was mainly larger than $3.3 \mathrm{~m}$, and the area ratio was $84 \%$ and $99.9 \%$, respectively. As shown in the "Monthly report of groundwater dynamic", groundwater depth was mainly larger than $4 \mathrm{~m}$ and was $2-4 \mathrm{~m}$ in a relatively small part from 2010 to 2015 . The area of the region where the groundwater depth was larger than $3.3 \mathrm{~m}$ increased to the whole region from 1980 to 2005 and the groundwater level went down consistently from 2000 to 2015 .

The precipitation and evaporation at Baicheng meteorological station did not show a significant changing trend with an approximately 40-year period. The mean precipitation and evaporation was $386 \mathrm{~mm}$ and $1194 \mathrm{~mm}$, respectively (Figure 4). From 1983 to 2006, the runoff of Taonan hydrological station fluctuated to decrease, except for a deluge in 1998 and after 2000, the runoff decreased to be nearly exhausted. Precipitation showed no typical spatial distribution pattern (Figure 5). From 1980 to 2015, the spatial distribution pattern of precipitation changed a lot. Evaporation showed two kinds of spatial distribution pattern, thus decreased from Southwest to Northeast and decreased from Southeast to Northwest. From 1980 to 2015, the change of evaporation spatial distribution pattern was not dramatic with $1700-2100 \mathrm{~mm}$ in domination. 
Table 3 Ratio between data number in typical groundwater depth interval and the whole data number in one well (\%)

\begin{tabular}{cccccccc}
\hline \multirow{2}{*}{ Well number } & \multicolumn{7}{c}{ Groundwater depth } \\
\cline { 2 - 8 } DA1 & \multicolumn{1}{c}{ 1.7 m } & $1.7-2.0 \mathrm{~m}$ & $2.0-2.2 \mathrm{~m}$ & $2.2-2.4 \mathrm{~m}$ & $2.4-3 \mathrm{~m}$ & $3-3.3 \mathrm{~m}$ & $>3.3 \mathrm{~m}$ \\
\hline TB1 & 0 & 0.7 & 1.2 & 0.8 & 5.0 & 2.5 & 89.8 \\
TB2 & 0 & 10.9 & 9.5 & 8.9 & 20.7 & 4.6 & 30.8 \\
TN1 & 47.5 & 8.2 & 0 & 0 & 10.0 & 16.0 & 74.0 \\
TN2 & 0 & 0 & 0 & 4.2 & 5.8 & 7.2 & 23.0 \\
TN3 & 2.3 & 1.4 & 0 & 1.1 & 11.9 & 13.7 & 73.4 \\
TN4 & 3.7 & 7.8 & 8.4 & 0 & 0 & 0 & 96.3 \\
TN5 & 0 & 0 & 0.1 & 1.8 & 12.2 & 9.4 & 76.6 \\
TY1 & 0 & 5.1 & 14.8 & 23.1 & 51.2 & 5.6 & 0.2 \\
TY2 & 18.8 & 8.3 & 5.9 & 6.1 & 13.4 & 3.4 & 44.2 \\
TY3 & 0 & 0 & 0 & 0 & 1.7 & 11.6 & 86.7 \\
TY4 & 8.8 & 7.9 & 6.7 & 5.1 & 20.9 & 11.3 & 39.3 \\
TY5 & 3.2 & 4.0 & 6.5 & 12.7 & 23.4 & 13.7 & 36.4 \\
TY6 & 0 & 0 & 2.0 & 5.1 & 16.0 & 11.4 & 65.6 \\
ZL1 & 0 & 0 & 0 & 0 & 0 & 0.4 & 99.6 \\
ZL2 & 0.2 & 1.4 & 2.5 & 1.9 & 7.6 & 4.1 & 82.1 \\
\hline
\end{tabular}
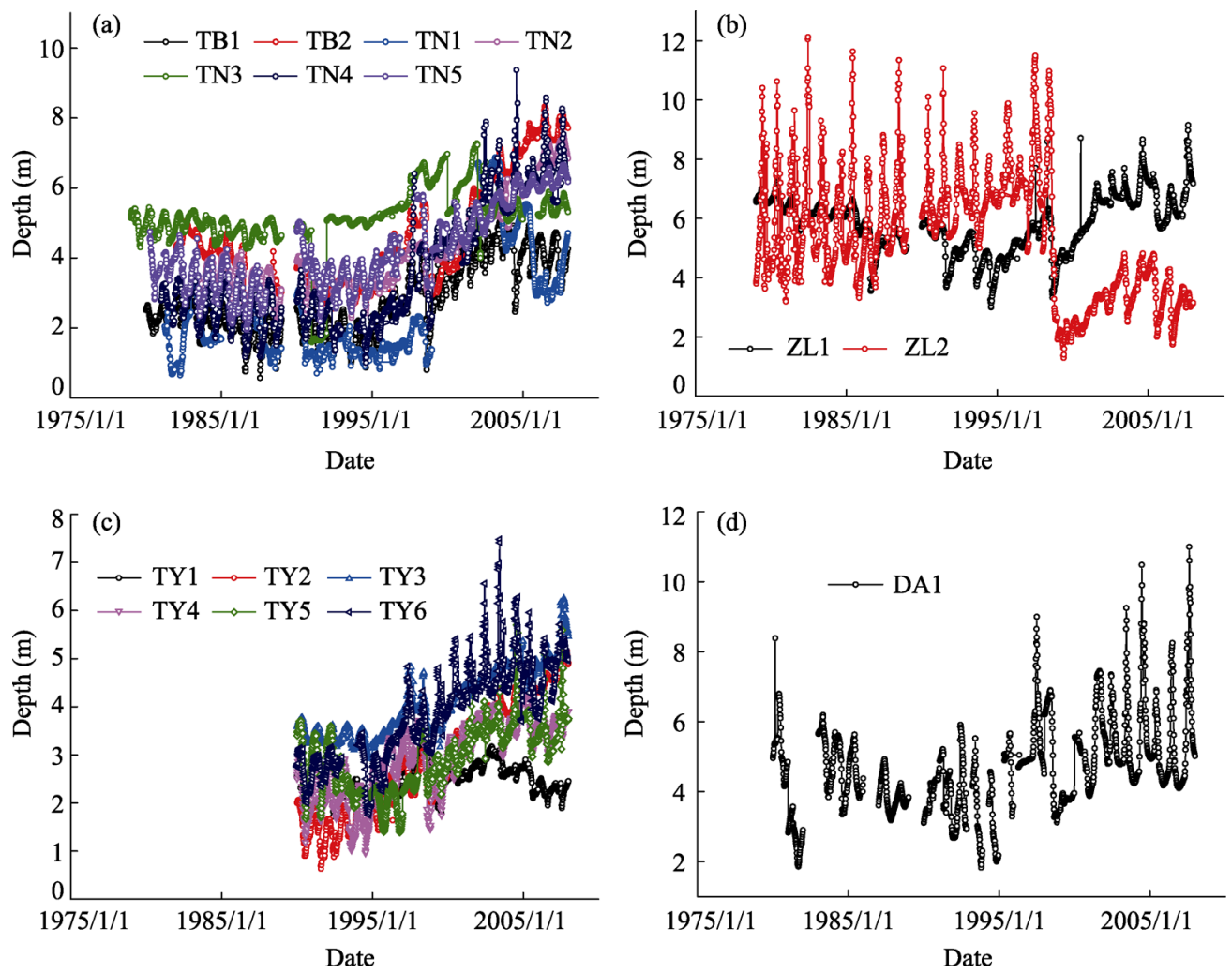

Figure 3 Temporal distribution of groundwater depth in the typical part of Songnen Plain 

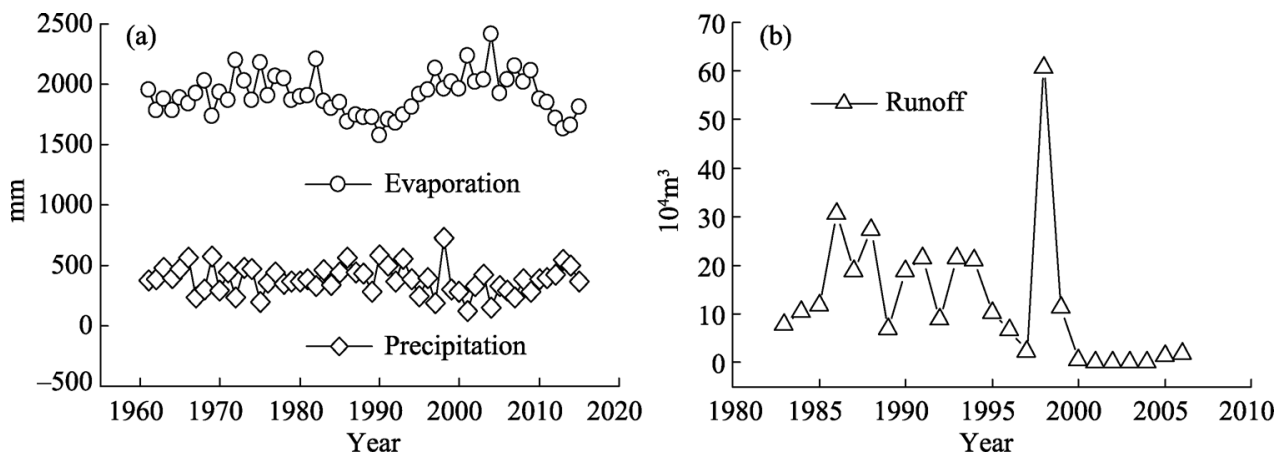

Figure 4 Temporal distribution of evaporation, precipitation and runoff in the typical part of Songnen Plain

(a) 1980

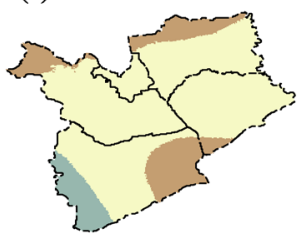

(e) 2010

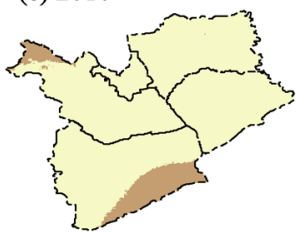

(g) 1980

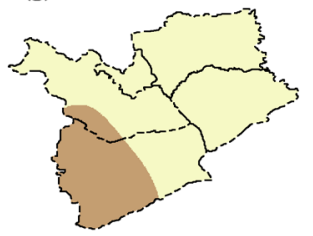

(k) 2010

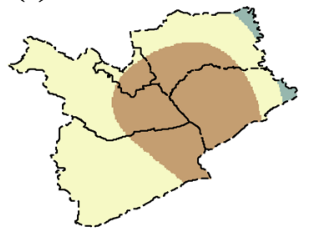

(m) 1980

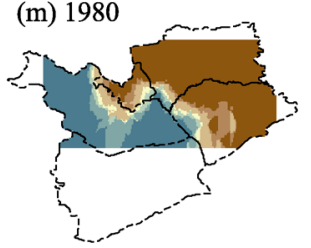

(b) 1990

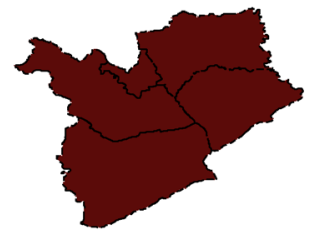

(f) 2015

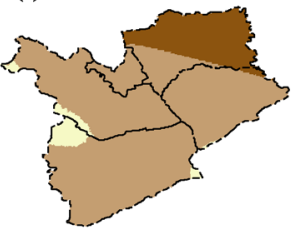

(h) 1990

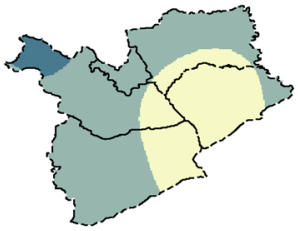

(1) 2015

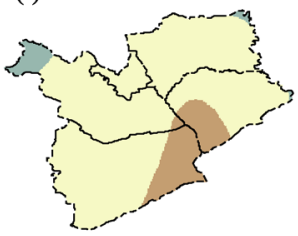

(n) 1990

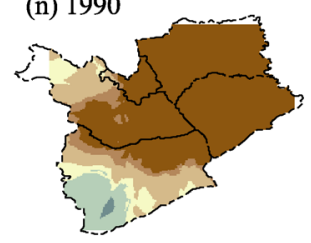

(c) 2000

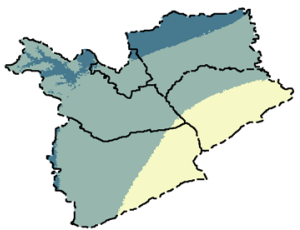

Precipitation (mm)

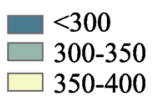

(i) 2000

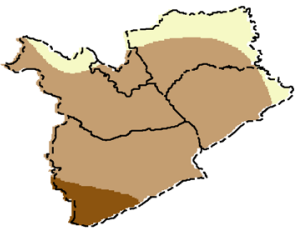

(j) 2005

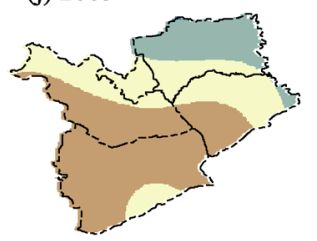

(d) 2005

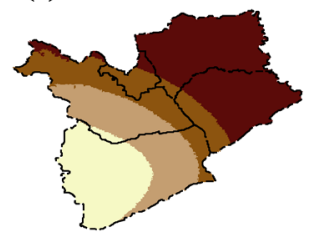

$\square 00-450$
$450-500$

- $>500$
Evaporation (mm)

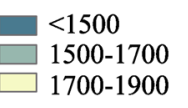

(o) 2000

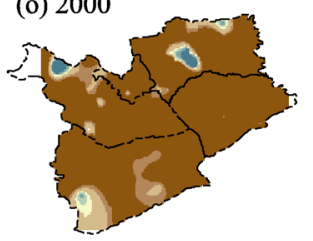

1900-2100

2100-2300

$>2300$

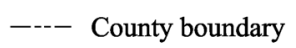

$$
0
$$

$250 \mathrm{~km}$

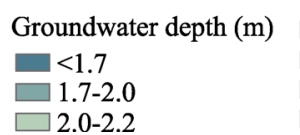

(p) 2005
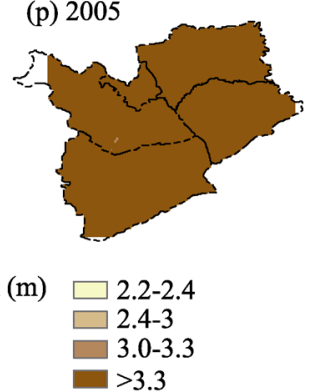

Figure 5 Spatial distribution of precipitation, evaporation and groundwater depth in the typical part of Songnen Plain 


\subsection{Causes of land salinization}

Land salinization was the result of salt aggregation on land surface. Any factors which could exert influence on the salt aggregation in the upper soil layer, such as change of evaporation interface, accessibility to land surface of groundwater, and so on, may cause the change of land salinization. Causes of land salinization were determined from land cover change and hydrological process change.

\subsubsection{Determination from land cover change}

From 1980 to 2015, saline land had close transfer relationship with cropland, grassland, and water body. This meant that the factors that could exert influence on the change of cropland, grassland, and water body may exert influence on the change of saline land. Even cropland was mainly composed of dry land, the ratio between the area of paddy field and the area of cropland increased from $4.9 \%$ in 1980 to $12.7 \%$ in 2015 . The increase of cropland included the increase of dry land and paddy field. From 1980 to 2015, the area of dry land increased from $8617 \mathrm{~km}^{2}$ to $10319 \mathrm{~km}^{2}$ (increased by $19.8 \%$ ), while, the area of paddy field increased from $447 \mathrm{~km}^{2}$ to $1502 \mathrm{~km}^{2}$ (increased by $236 \%$ ). The amount of water for irrigation mainly depended on the area of paddy field, so that the high speed increase of area of paddy field highly increased the irrigation amount which was the main reason for secondary land salinization.

Change of grassland was composed of change of high coverage grassland and middle coverage grassland. From 1980 to 2015, high coverage grassland decreased from $3672 \mathrm{~km}^{2}$ to $1519 \mathrm{~km}^{2}$ (decreased by $58.6 \%$ ), and middle coverage grassland decreased from $2645 \mathrm{~km}^{2}$ to $1760 \mathrm{~km}^{2}$ (decreased by $33.5 \%$ ), respectively. The change of area of grassland mainly happened in the period from 1980 to 2000. In this period, cropland, water body, and saline land were the major land cover transformation types. Grassland included high coverage grassland and middle coverage grassland. From 1980 to 2000, high coverage grassland mainly transformed into cropland and middle coverage grassland, middle coverage grassland mainly transformed into saline land, and low coverage grassland mainly transformed into saline land and dry land. Transformation from grassland to saline land was a direct reason for land salinization and transformation from grassland to cropland increased the risk of land salinization.

Change of water body referred to change of lake and flood plain. From 1980 to 2015, lake decreased from $1370 \mathrm{~km}^{2}$ to $797 \mathrm{~km}^{2}$ (decreased by $41.8 \%$ ), and flood plain increased from $207 \mathrm{~km}^{2}$ to $339 \mathrm{~km}^{2}$ (increased by $63.8 \%$ ), respectively. From 1980 to 2015, the areas of lake changed to paddy field, dry land, middle coverage grassland, flood plain, saline land, and swampland were $14 \mathrm{~km}^{2}, 103 \mathrm{~km}^{2}, 18 \mathrm{~km}^{2}, 122 \mathrm{~km}^{2}, 192 \mathrm{~km}^{2}$, and $182 \mathrm{~km}^{2}$, respectively, while, the area of flood plain changed to dry land was $11 \mathrm{~km}^{2}$. The transformation from lake to saline land was a direct reason and transformation from lake or flood plain to shallow water area, middle coverage grassland, and dry land increased the risk of land salinization.

\subsubsection{Determination from hydrological process change}

Besides interface of water movement, change of water movement process was also a vital factor for land salinization. Rise of groundwater was a major reason of land salinization, so the completeness of rise to the ground surface was a necessary condition for evaporation. Based on the previous study in Songnen Plain (GSIJP, 2006) (Table 4), $3.3 \mathrm{~m}$ of the 
groundwater depth was seen as a critical value that groundwater could cause land salinization. In the typical part of Songnen Plain, from 1979 to 2015, groundwater depth was larger than $3.3 \mathrm{~m}$ in most of the cases. The ratio between the area of the region where groundwater depth was larger than $3.3 \mathrm{~m}$ and the whole region increased from $46.7 \%$ in 1980 to $84 \%$ in 2000 , and then increased from $92.6 \%$ in 2001 to $99.9 \%$ in 2005 . The region where groundwater depth was larger than $3.3 \mathrm{~m}$ almost occupied the whole region steadily from 2005 to 2015. Before 2000, the relatively shallow groundwater was an important reason for land salinization, while, after 2000, the groundwater with relatively large depth was not a direct reason for land salinization.

Table 4 Groundwater depth threshold induced for soil salinization in Songnen Plain (Geological Survey Institute of Jilin Province, 2006)

\begin{tabular}{ccc}
\hline Soil texture & Soil salinization level & Groundwater depth threshold $(\mathrm{m})$ \\
\hline Sandy loam & Non & $>3.3$ \\
& Light & $2.4-3.3$ \\
& Middle & $2.0-2.4$ \\
& Heavy & $<2.0$ \\
Clay loam & Non & $>3.0$ \\
& Light & $2.2-3.0$ \\
& Middle & $1.7-2.2$ \\
& Heavy & $<1.7$ \\
\hline
\end{tabular}

In the typical part of Songnen Plain, evaporation was bigger than precipitation. In this area, evaporation was the major discharge manner. With a large amount of cropland and insufficient precipitation and surface water runoff, irrigation, which came from deep groundwater, river, lake, and transferred water from outer basin, was an important water source for cropland. Reduction of surface water runoff and addition of irrigation produced a phenomenon that area of the region with long time waterlogging decreased and area of the region waterlogged temporarily increased. It increased the cycle of vertical leach and evaporation process, which was the key process of land salinization. The area of paddy field and flood plain increased by $1026 \mathrm{~km}^{2}$ from 1980 to 2000, and then increased by $161 \mathrm{~km}^{2}$ from 2000 to 2015 (Figure 6). The area of river, lake, water reservoir, and swampland decreased by 873

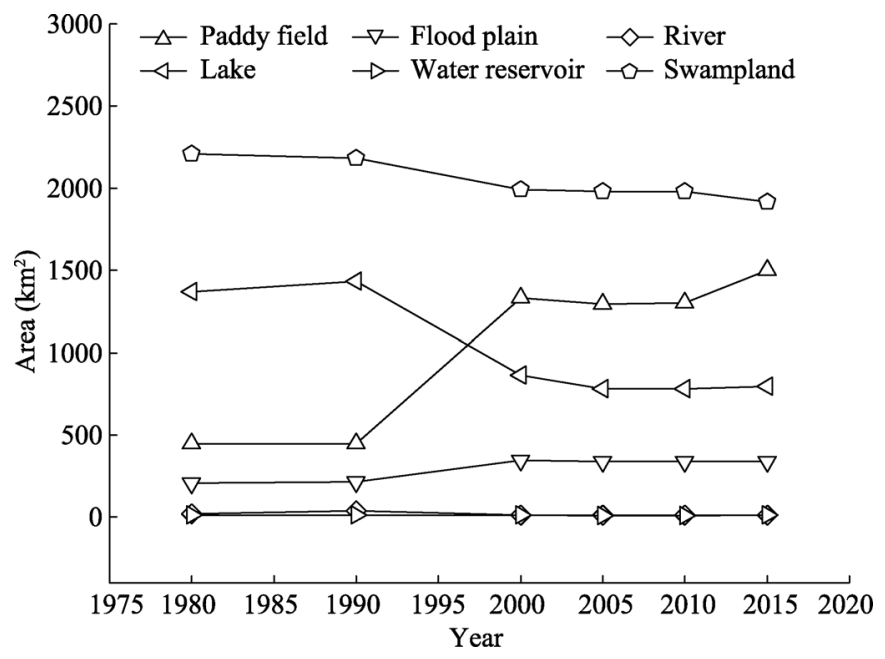

Figure 6 Change of area of region covered by water in the typical part of Songnen Plain 
$\mathrm{km}^{2}$ from 1980 to 2000 , and then decreased by $142 \mathrm{~km}^{2}$ from 2000 to 2015 . Before 2000 , the increase of the area of shallow waterlogging region and the decrease of the area of deep water body exerted much influence on the increase of saline land. After 2000, the area of the region covered by the water and the area of saline land both kept relatively stable.

\section{Discussion}

At different spatio-temporal scales, different factors had different influences on the occurrence and development of land salinization. Most studies focused on the influence from the shallow groundwater and the rise process of the soil salt. In natural process, shallow groundwater determined the salt aggregation of the land surface. While, when the hydrological process was interrupted by comprehensive human activities, the mechanism of salt aggregation changed into a complex pattern. Yang et al. (2010) depicted a mechanism through analyzing the transport process of soil water and salt, thus, in Songnen Plain, human activities had changed the surface hydrological process, and significantly decreased the ponding chances and occurrence frequency of rainwater and runoff. The ponding rainwater drove the salt accumulated in the upper soil from the depression to the hilltop, and formed the new distribution pattern of salt-affected soils. The shallow groundwater was not a main cause of the ongoing secondary soil salinization, although it played a significant role at early stages in the primary soil salinization. Liu et al. (2005) indicated that the hydrological change induced from the land use change was the main driving factors. The relationship between the increased saline land area and the distance to the water body edge indicated that the increase of saline land came from the dynamic of water body.

In this study, the area of saline land increased constantly from 1980 to 2000, and kept stable after 2000. The transformation among land covers showed that cropland, grassland, and water body had close transformation relationship with saline land. Moreover, there was also close transformation relationship among cropland, grassland, and water body, especially before 2000. Increase of paddy field, dry land, middle coverage grassland, low coverage grassland, and the nearly dry land surface including flood plain and swampland provided a large amount of interface for evaporation, which could carry soil salt to the ground surface. The area of the region where groundwater depth was larger than $3.3 \mathrm{~m}$ increased from 1980 to 2000, while, the area occupied almost the whole region after 2000. From 1980 to 2000, shallow groundwater could lead to land salinization, but was not the most important reason for the increase of saline land. Because the area of saline land increased when the area of the region where groundwater depth was larger than $3.3 \mathrm{~m}$ increased. Change of cropland, grassland, and water body induced from human activities and decrease of runoff and increase of irrigation and water transfer from outer basin were the main reasons for the increase of saline land from 1980 to 2000. After 2000, groundwater with relatively large depth could not exert much influence on land salinization. Protection of grassland and wetland prevented the increase of the area of saline land.

\section{Conclusions}

Land salinization was a severe and typical problem at the typical part of Songnen Plain. Land cover database and hydrological data were collected for analysis of spatio-temporal 
change of saline land and hydrological process and causes of land salinization were determined from the transformation of saline land with other kinds of land covers and the change of hydrological processes. Conclusions had been gotten as follows:

1) The area of saline land increased from $4627 \mathrm{~km}^{2}$ in 1980 to $5416 \mathrm{~km}^{2}$ in 2000 , and then decreased to $5198 \mathrm{~km}^{2}$ in 2015 . Saline land almost distributed in the whole region, except the northwest part of the study area. The transformation between saline land and other kinds of land covers mainly before 2000, and transformation among saline land, cropland, grassland, and water body were the major transfer types.

2) From 1979 to 2007, groundwater depth of the 16 wells was mainly larger than $3.3 \mathrm{~m}$ and had an increasing trend. Seasonally, the groundwater rose in spring, dropped down in summer with fluctuation, and rose again in autumn and winter. Spatially, the area of the region where the groundwater depth was larger than $3.3 \mathrm{~m}$ increased from 1980 to 2000, while the region almost occupied the whole region after 2000. Precipitation and evaporation changed little, while runoff decreased very much.

3) Groundwater could exert influence on land salinization before 2000. The nearly dried-up runoff, increase of paddy field (198.2\%) and flood plain (67.6\%), and decrease of high coverage grassland (52.3\%), middle coverage grassland (36.8\%), and lake (36.9\%) increased the area of interface of vertical water movement, which increased the area of saline land indirectly. Change of cropland, grassland, and water body induced from human activities and the decrease of runoff and the increase of irrigation and water transfer from outer basin were the main reasons for the increase of saline land from 1980 to 2000. After 2000, groundwater with relatively large depth could not exert much influence on land salinization directly. Protection of grassland and wetland prevented the increase of the area of saline land.

\section{Acknowledgements}

The authors extend their thanks to Prof. Guangxin Zhang (Northeast Institute of Geography and Agroecology, Chinese Academy of Sciences) for generously providing us data on groundwater depth.

\section{References}

Akhtar A, Shahbaz K, Nisar H et al., 2013. Characterizing soil salinity in irrigated agriculture using a remote sensing approach. Physics and Chemistry of the Earth, 55-57: 43-52.

Datta K K, deJong C, 2002. Adverse effect of waterlogging and soil salinity on crop and land productivity in northwest region of Haryana, India. Agricultural Water Management, 57(3): 223-238.

Ding J L, Wu M C, Tashpolat T, 2011. Study on soil salinization information in arid region using remote sensing technique. Agricultural Sciences in China, 10(3): 404-411. (in Chinese)

FAO, 2007. Extent and causes of salt-affected soils in participating countries. AGL: Global Network on Integrated Soil Management for Sustainable Use of Salt-affected Soils. http://www.fao.org/ag/agl/agll/spush/topic2.htm.

García-Ruiz M J, 2010. The effects of land uses on soil erosion in Spain: A review. Catena, 81(1): 1-11.

Geological Survey Institute of Jilin Province (GSIJP), 2006. Evaluation of groundwater resources and environmental problems in Songnen Plain. (in Chinese)

Gu H B, Song Y, Pan J, 2010. Research progress of influencing factors on salinization of Songnen Plain. Journal of Anhui Agricultural Science, 38(30): 95-98. (in Chinese)

Ha X P, Ding J L, Tiyip T et al., 2006. SI-albedo space-based extraction of salinization information in arid area. Acta Pedologica Sinica, 46(4): 698-703. (in Chinese) 
Halse S A, Ruprecht J K, Pinder A M et al., 2003. Salinisation and prospects for biodiversity in rivers and wetlands of south-west Western Australia. Australian Journal of Botany, 51(6): 673-688.

Khan N M, Sato Y, 2001. Monitoring hydro-salinity status and its impact in irrigated semi-arid areas using IRS-1B LISS-II data. Asian J. Geoinform, 1(3): 63-73.

Lai N, Li X G, Tuerdi A et al., 2014. Dynamic changes of the salt-affected soil in the oasis of the lower reaches of Kaidu River in the recent 50 years. Remote Sensing Information, 29(3): 35-43.

Lambert K S, Shiati K, 2002. Irrigation and salinity: A perspective review of the salinity hazards of irrigation development in the arid zone. Irrigation and Drainage Systems, 16(2): 161-174.

Li X, Qiao M, Zhou S, 2016. Causes and spatial-temporal changes of soil salinization in Manasi irrigation region of Xinjiang Region during 1985-2014. Bulletin of Soil and Water Conservation, 36(3): 152-158.

Line J G, Finlaysonc C M, Falkenmark M, 2010. Managing water in agriculture for food production and other ecosystem services. Agricultural Water Management, 97(4): 512-519.

Liu G M, Yang J S, Li D S, 2002. Evaporation regularity and its relationship with soil salt. Acta Pedologica Sinica, 39 (3): 384-389. (in Chinese)

Liu J, Zhang Z, Xu X et al., 2010. Spatial patterns and driving forces of land use change in China during the early 21 st century. Journal of Geographical Sciences, 20(4): 483-494.

Liu L, Chen X, Xu X L et al., 2014. Changes in production potential in China in response to climate change from 1960 to 2010. Advances in Meteorology, 1-10.

Liu L, Xu X L, Liu J Y et al., 2015. Impact of farmland changes on production potential in China during 1990-2010. Journal of Geographical Sciences, 25(1): 19-34

Liu Q, He Y, Deng W et al., 2005. Study on the soil salinization process in the changeable environment: A case study in the middle and lower reaches of Taoer River. Journal of Arid Land Resources and Environment, 19(6): 113-117. (in Chinese)

Masoud A A, Koike K, 2006. Arid land salinization detected by remotely-sensed land cover changes: A case study in the Siwa region, NW Egypt. Journal of Arid Environments, 66(1): 151-167.

Metternicht G I, Zinck J A, 2003. Remote sensing of soil salinity: Potentials and constraints. Remote Sensing of Environment, 85: 1-20.

Mulder V L, Bruin S, Schaepman M E et al., 2011. The use of remote sensing in soil and terrain mapping: A review. Geoderma, 162(1/2): 1-9.

Poenaru V, Badea A, Cimpeanu S M et al., 2015. Multi-temporal multi-spectral and radar remote sensing for agricultural monitoring in the Braila Plain. Agriculture and Agricultural Science Procedia, 6: 506-516.

Qadir M, Tubeileh A, Akht J et al., 2008. Productivity enhancement of salt-affected environments through crop diversification. Land Degradation \& Development, 19(4): 429-453.

Rengasamy P, 2002. Transient salinity and subsoil constraints to dryland farming in Australian sodic soils: An overview. Australian Journal of Experimental Agriculture, 42(3): 351-361.

Song C C, Deng W, 2000. Characters of groundwater and influence on the interior salt-affected soil in the West of Jilin Province. Scientia Geographica Sinica, 20(3): 246-230. (in Chinese)

UNEP, 1991. Status of desertification and implementation of the United Nations plan of action to combat desertification. Nairobi, Kenya.

Wang F, Chen X, Luo G et al., 2013. Detecting soil salinity with arid fraction integrated index and salinity index in feature space using Landsat TM imagery. Journal of Arid Land, 5: 340-353.

Wang L, Seki K, Miyazaki T et al., 2009. The causes of soil alkalinization in the Songnen Plain of Northeast China. Paddy Water Environ., 7: 259-270.

Wang Z X, Su Q S, Lin S Z et al., 1985. Groundwater and Quaternary Geology at Baicheng. Beijing: Geological Publishing House. (in Chinese)

Yamaguchi T, Blumwald E, 2005. Developing salt-tolerant crop plants: Challenges and opportunities. Trends in Plant Science, 10(12): 615-620.

Yang J, Zhang G, 2010. Effect of hydrological process change on soil salinization in western Songnen Plain. Journal of Arid Land Resources and Environment, 14(9): 168-172. (in Chinese)

Yu R P, You W R, 1993. Monitor and Prevention of Salt-affected Soil. Beijing: Science Press, 41-49. (in Chinese)

Zhang D F, 2000. Study on soil salinization in the Western Plain of Jilin Province based on GIS [D]. Changchun: Changchun University of Science and Technology. (in Chinese) 